\title{
The role of epidemiology and surveillance systems in the control of sexually transmitted diseases
}

Review

\author{
M A Catchpole
}

Surveillance and epidemiological studies are essential components of effective control programmes for sexually transmitted diseases. While other forms of basic biomedical research may add to our understanding of why an exposure or behaviour causes or prevents disease, only epidemiology allows the quantification of the magnitude of the exposure-disease relationship in humans. It is this measure of the association between risk and disease that is needed to inform rational policy on altering risk through intervention. Surveillance data are used both to determine the need for public health action and to assess the effectiveness of programmes: they are required for the setting of priorities, for planning and resource allocation, for the definition of population subgroups and risky behaviours for targeted interventions, for the development of disease prevention programmes, and for the evaluation of interventions. Data from surveillance systems and epidemiological studies can also inform diagnostic and therapeutic practice, and indicate areas for further research.

Over the last 20 years chlamydia infections and viral agents have emerged as the major cause of STD in developed countries, and with this change in the aetiological mix of STD cases the focus of prevention and control of STDs has shifted from treatment and partner notification towards health education. In developing countries there is an urgent need for appropriate surveillance infrastructures, particularly now that there is evidence that STD control programmes, informed by surveillance data, can reduce HIV transmission at the population level. The importance of surveillance and epidemiology in the control of STDs is set to increase in the face of the changing pattern of sexually transmitted pathogens. The challenge to clinicians and epidemiologists is to work together in developing systems that will inform new approaches to control and prevention.

(Genitourin Med 1996;72:321-329)

Keywords: epidemiology; STD surveillance

\section{Introduction}

Sexually transmitted disease (STD) control has two main aims: to interrupt the transmission of infection and to prevent the development of complications and sequelae. To achieve these goals we need to know which exposures might result in transmission and which treatments or interventions might modify the risks of exposure or the course of infection. In order to set priorities within control programmes we also need to know the magnitude of the risk associated with exposure, both at the individual and the population level, and the potential size of the impact of interventions. While other forms of basic biomedical research may add to our understanding of why an exposure or behaviour causes or prevents disease, only epidemiology allows the quantification of the magnitude of the exposuredisease relationship in humans. It is this measure of the association between risk and disease that is needed to inform rational policy on altering risk through intervention. Epidemiological research and surveillance has often provided information that has formed the basis for public health decisions long before the basic mechanism of a particular disease was understood. By the time the human immunodeficiency virus (HIV) had been isolated in 1983, epidemiological studies had provided much of the information that underpins current HIV prevention efforts: that AIDS was caused by a transmissible agent, that it was most probably transmitted through sexual contact and blood product transfusion, and that the agent was likely to be a virus. On the basis of these findings control measures were recommended in the USA prior to the discovery of HIV. ${ }^{1}$

The dramatic reduction in the incidence of gonorrhoea and syphilis that has been seen over the last two decades in many industrialised countries is largely due to developments in clinical services in those countries, including the widespread availability of reliable diagnostic tests, effective antibiotic therapy, and partner notification. Behavioural changes following the advent of AIDS probably also contributed to this decline latterly, ${ }^{2}$ although incidence rates were falling before the arrival of AIDS and behavioural change seems not to have been sustained. ${ }^{3}$ Pharmaceutical developments and clinical trials may further improve our ability to control the spread of these bacterial diseases, but, unless effective vaccines or new drugs that can eliminate viral infections are developed, such research can only be expected to have a modest impact on the spread of the viral STDs, which are now more common than gonorrhoea and syphilis in many industrialised countries. ${ }^{45}$ Primary prevention, through health education and behaviour modification, offers the only effective means of controlling HIV and the
Disease Surveillance Centre, Colindal Avenue, Londo M A Catchpole

Accepted for publication 7 August 1996 
Uses of surveillance data

- Setting of priorities

Planning and allocating resources for services

- Defining population subgroups and risky behaviours for targeted interventions

Directing public health policy

Informing diagnostic and therapeutic practice

Evaluation of interventions

Stimulating further research

other viral STDs. Epidemiological and behavioural research is required to define target groups for primary prevention and to identify the behaviours that are associated with higher risk of infection. In developing countries improvement of control of bacterial STDs remains a priority. ${ }^{6}$ Surveillance and epidemiology also have a major role in these often resource-poor settings, in establishing priorities and guiding diagnostic and therapeutic decision making.

\section{Surveillance and epidemiology and their role in STD control}

Epidemiology is the study of the distribution and determinants of health-related states or events in defined populations. ${ }^{7}$ Epidemiological data may be gathered through time-limited cross-sectional or longitudinal studies or through continuous surveillance systems. The main purpose of surveillance has been defined as the detection of changes in trend or distribution in order to initiate investigative or control measures. ${ }^{7}$ Surveillance systems and descriptive epidemiological studies provide descriptions of the frequency, distribution, and trends of disease within populations. Analytical studies, including randomised controlled trials, also provide measures of the strength of the association between particular characteristics, behaviours, exposures, or interventions and the occurrence of disease. Surveillance data are used both to determine the need for public health action and to assess the effectiveness of programmes:

STDs are unique among infectious diseases in the problems that they pose epidemiologists and those responsible for the control and prevention of these diseases. Collection of data and outreach of prevention programmes is made difficult by the fact that the highest prevalences of STDs are frequently to be found within socially marginalised or stigmatised groups, such as prostitutes ${ }^{8}$ and substance abusers, ${ }^{9}$ or within population groups that are relatively inaccessible to epidemiologists and health educators, such as adolescents, ${ }^{10}$ particularly those that have left full-time education. Further difficulties arise from the fact that many cases of STD may go undetected because of the high frequency of asymptomatic infection associated with some conditions, and the tendency, in some countries, for STD patients to seek care outside mainstream health services, either in private clinics or from traditional healers. ${ }^{11} 12$

\section{Setting priorities and planning services \\ In Historical perspectives}

Epidemiological surveys and surveillance have provided data that have greatly influenced STD control over the last 150 years, by prompting legislation or stimulating the development of clinical services. Examples range from early surveys of the prevalence of venereal diseases in many industrialised countries in the nineteenth and early twentieth century to the use of surveillance data ${ }^{13}$ for recent estimates of the cost to national economies of STDs by the World Bank.

The accumulation of data from surveys of STD prevalence during the nineteenth and early twentieth centuries was a major stimulus in several countries to the passing of legislation that still underpins today's systems for the control of STDs. The Royal Commission on Venereal Diseases was established in Britain in 1913 as a response to the lobbying of medical and philanthropic factions. These bodies were motivated by surveys including those demonstrating that by 1863 venereal disease accounted for one-third of cases of sickness among the country's armed forces ${ }^{14}$ and for 1 in 14 of the poor demanding attention at medical institutions in London, ${ }^{15}$ and that high rates of venereal disease existed among inmates of workhouses. ${ }^{16}$ Similarly, when the Ontario government appointed its own one-man Royal Commission into Venereal Diseases and Feeblemindedness in 1917, it was in part in response to the finding that $12-13 \%$ of public ward patients attending the Toronto General Hospital had positive Wassermann tests. ${ }^{17}$ In Germany, the results of a national survey of the incidence of STDs, carried out in 1919, increased the pressure for legislation, eventually passed in 1927, on the control of these diseases. ${ }^{18}$ With the passing of legislation on the control of STDs came the establishment of specialist clinical services for STDs and/or the inclusion of STDs in the list of notifiable diseases in many countries. These changes improved the quality of STD surveillance data and allowed trends in disease incidence to be monitored and the impact of control programmes to be assessed.

During the 1970s and 1980s the development of new laboratory techniques increased the range of investigations available to clinicians diagnosing and treating STD patients. These advances had the effect of increasing the range of pathogens that were recognised as causes of STDs, and revealed previously unsuspected complications of STDs. ${ }^{19}$ The discovery of a HIV and the development of diagnostic tests for this infection was a major step forward for surveillance. In recent years some of the most significant advances in surveillance have been in the development of new methodologies, such as the unlinked anonymous method for HIV surveillance, ${ }^{20}$ and in the analytical approaches to surveillance data, such as the refinement of techniques used to estimate projections of disease incidence, particularly AIDS. ${ }^{21}$

\section{(2) New challenges}

Since the advent of AIDS, priority setting and planning of services for patients with AIDS and other STDs has assumed a much higher political profile, and with this has come a more 
critical approach to surveillance data. Surveillance systems and epidemiological surveys should aim to provide information on all cases of STDs, including those seen outside specialist clinics, if they are to support rational setting of priorities in disease control and the planning and allocation of resources for services. For much of the twentieth century STD surveillance in developed countries has been based on notifications of cases from physicians or on statistical returns from clinics offering services for the treatment and diagnosis of these diseases. ${ }^{22}$ The data tend to reflect only the "contact surface" between these clinics and their attenders, which may be restricted to rather limited social groups or strata of the population. Under-reporting of cases of STDs has been recognised as a longterm problem in many countries ${ }^{172324}$ as has failure to detect cases seen outside specialist clinics. ${ }^{25} 26$ There are very few reliable data on the sequelae of STDs, such as pelvic inflammatory disease, despite the fact that these conditions are the cause of much of the burden of morbidity associated with STDs. Development of surveillance systems for these diseases is required if the true costs of STDs are to be estimated, and because reduction in the incidence of sequelae is an important outcome measure for STD control programmes.

Epidemiologists and clinicians must be alert to these deficiencies and improve existing systems or develop new systems where appropriate. In Italy, Greco and colleagues demonstrated significant levels of underreporting of gonorrhoea and syphilis, ${ }^{23}$ and in response developed a new sentinel surveillance system. ${ }^{27}$ In England the Public Health Laboratory Service is coordinating a study of cases of STD seen in general practice, and a pilot sentinel surveillance network of genitourinary medicine (GUM) clinics that will collect behavioural and augmented demographic data. In the United Kingdom ${ }^{28-31}$ the USA, ${ }^{32}{ }^{33}$ Canada, ${ }^{34}$ Sweden, ${ }^{35}$ and Holland, ${ }^{36}$ surveys have demonstrated substantial levels of genital chlamydia infection among attenders of health services other than STD or GUM clinics. In England the results of these surveys suggest that a significant proportion of genital chlamydial infections are not seen in GUM clinics; indicating that this STD cannot be controlled through the treatment and notification of partners of cases seen in GUM clinics alone. New approaches to the control of chlamydia in Scandinavia ${ }^{37}$ and the USA, ${ }^{38}$ stimulated by such results, appear to be successfully reducing the incidence not only of cases of lower genital tract chlamydia infection but also the incidence of sequelae.

\section{(3) Developing countries}

Parallels may be drawn between the problems associated with the control of STDs in industrialised countries in the early part of the twentieth century and those associated with the control of STDs in developing countries today. There have been repeated calls for a change in attitude of health administrators in developing countries to recognise that STDs and their complications are a serious problem and require energetic control measures. ${ }^{39} 40$ Piot and Islam ${ }^{40}$ have suggested that the major challenges in the control of STDs in developing countries are the mobilisation of political commitment and funds, and the translation of small scale interventions into large scale public health programmes. Epidemiological data from surveillance systems and ad hoc studies are essential if these challenges are to be met. Although the scale of the problem of STDs in Africa has long been recognised, ${ }^{39} 41$ and early reports of high prevalences in SE Asia are also to be found, ${ }^{42}$ it is only in recent years that prevalence studies were conducted in many developing countries. These studies have reported rates that vary enormously between countries and population groups studied, but even the lowest rates reported are at least 10 times higher than those in comparable populations in developed countries. ${ }^{40}$ Just as prevalence data on venereal diseases in the nineteenth and early twentieth century were used to stimulate political action in Europe and North America so can such data be used to stimulate investment in STD control programmes in developing countries. The prevalence of bacterial diseases such as syphilis and gonorrhoea in many developing countries is indeed similar to that seen in nineteenth century Europe. The lesson from the past, however, is that the production of statistics, while necessary, is not sufficient to evoke action.

The challenge for those involved in surveillance or epidemiological studies is to present their data in ways that will evoke effective control measures, and to ensure that control programmes are data driven. It will be important to show the effectiveness, and the cost effectiveness, of STD control programmes, if resources are to be secured. In this respect there are some encouraging results from recent studies in Africa $^{43}$ and Asia. ${ }^{44}$ Demonstrations of the true cost of STDs to national economies are also likely to move STDs up the political agenda. Examples from Africa of such estimates include the calculation that in the early 1980 s the medical costs related to gonorrhoea alone were $17 \%$ of the budget for medicines, and $4 \cdot 3 \%$ of the overall health budget in one country, ${ }^{45}$ and that in Uganda STDs accounted for $16 \%$ of all admissions in some hospitals. ${ }^{41}$ More recently, the World Bank has used prevalence data to estimate that for females between 15 and 44 years of age in the developing world, STDs not including HIV infection are second only to maternal morbidity and mortality as a cause of healthy life lost, while for men, HIV ranks first as a cause of healthy life lost. ${ }^{13}$

\section{Informing public health practice}

Over the last 100 years, primary prevention has evolved from gender stereotyped exhortations to moral conduct to explicit advertisements and educational materials aimed directly at high risk groups. ${ }^{17}$ The first reference to syphilis control in the British Isles, from the council records of Aberdeen for 
1497, epitomises the earliest approaches to STD prevention: The said day, it was statut and ordanit be the alderman and consale for the eschevin of the infirmitey cumm out of Franche and strang partis, that all licht weman be chargit and ordaint to decist fra thar vicis and syne of venerie, and all thair buthis and houssis skalit, and thai to pas and wirk for thar sustentacioun, under the payne of ane key of het yrne one thar chekis, and banysene of the towne. ${ }^{46}$

This may be loosely translated as that day, the magistrate and council decreed that to control the disease from France and foreign parts, all lecherous women be ordered to desist from their vices and sins of lust, and that all their booths and houses be cleared, and that they work for their living, on pain of being branded on their cheek with a hot iron, and being banished from the town. There was little change in this approach to STD control, based on compulsory measures that were focused on prostitutes, ${ }^{47}$ until the twentieth century. The change in attitudes to STDs that is reflected in shifting approaches to prevention in this century has been influenced by data collected through surveillance and epidemiological studies: data that have demonstrated that STDs are prevalent within all strata of society, data that show that core groups within which there is frequent partner change play a key role in determining the epidemiology of STDs, and data on the effectiveness of various interventions. A better understanding of the determinants of STD epidemiology is essential to the development of more effective approaches to STD control. Such information will also allow us to predict the limitations of each single intervention, be it medical or behavioural.

Differences in the epidemiology of HIV infection around the world have long been a recognised feature of the global pandemic. ${ }^{48}$ Investigation of the reasons for these differences, in particular the study of the epidemiological synergy between HIV and other STDs $^{49}$ has been a major area of activity over the last 10 years. There is a growing body of evidence for the risk of HIV transmission being increased by STDs, and emerging evidence that HIV infection may increase the prevalence of some STDs. ${ }^{50}$ It is critical to the development of optimal strategies for HIV control that we understand the role of other STDs in the transmission of HIV, the role of STDs in the progression of HIV disease, and the role of HIV infection in altering the natural history, diagnosis, or response to therapy of STDs. ${ }^{50}$ The recognition of this interaction between HIV and STDs has led to the development of new strategies for HIV prevention, 435152 particularly for developing countries. The most notable example of such strategies is the randomised controlled trial of the impact of improved treatment of STDs on HIV infection in the Mwanza, ${ }^{43}$ which demonstrated that improved treatment of symptomatic STDs reduced HIV incidence by about $40 \%$ in a rural population in Tanzania. Epidemiological studies demonstrating substantial reservoirs of asymptomatic infection in sub-Saharan Africa, have also prompted a population-based mass STD treatment programme in rural Uganda. ${ }^{53}$

Factors that affect health care utilisation will affect the incidence of STDs for which there are curative treatments, and this can be expected, from the results of the Mwanza study, to affect the incidence of HIV. Epidemiological studies can provide measures of the impact of changes that affect the accessibility and acceptability of clinical services. Moses et al. studied the impact of a shortlived policy of charging fees to patients attending public-sector outpatient STD treatment facilities in Kenya. ${ }^{54}$ They found that the introduction of user fees probably increased the number of untreated STDs in the population, with potentially serious longterm implications for STD control in Kenya, and recommended caution in introducing fees elsewhere. Surveillance data can also be used in the audit of clinical services. New techniques, such as the unlinked anonymous method of HIV surveillance, are providing insight on the effectiveness of routine case detection methods in identifying all HIV-infected health service attenders. In both the USA and the United Kingdom there is evidence from these surveys that significant numbers of HIV infections are not being detected, even among attenders at GUM or STD clinics. ${ }^{556}$

\section{Informing clinical practice}

In most developing countries clinical services for STD patients, if they are available at all in the public sector, are provided as part of primary health care. Providers of primary health care do not usually have access to sophisticated diagnostic facilities, and therefore simple management protocols, usually based on a problem-orientated approach, are needed..$^{45}$ In such situations, surveillance data are essential in providing information on the local aetiology of a problem. The recent finding of genital chlamydia infection among $45 \%$ of STD clinic attenders in Malagasy, where chlamydia diagnosis had not previously been possible in public facilities, led to the recommendation that future treatment algorithms for urethritis encourage the use of combined treatment for chlamydia and gonorrhoea. ${ }^{57}$ Similarly, in the Mwanza study, algorithms were designed to provide effective treatment for the organisms mainly responsible for the common STD syndromes in eastern Africa. ${ }^{58}$

In many developing countries antimicrobial resistance is a major problem, with epidemiological surveys demonstrating that penicillinase producing Neisseria gonorrhoeae (PPNG) represent at least $50 \%$ of gonococcal infections in Africa, ${ }^{5960}$ and that resistance to tetracycline and other antimicrobials is increasing rapidly. ${ }^{61}$ Monitoring of antimicrobial susceptibility of STD agents has also become important in developed countries because highly variable susceptibility patterns are now common, particularly among gonococcal strains. Laboratory based surveillance systems, or intermittent surveys, can contribute information on antimicrobial susceptibilities that can 
guide policy on treatment of STDs. Results of studies such as these led WHO to recommend that penicillins and tetracyclines should not be used in the treatment of gonorrhoea in Africa, SE Asia, and the Western Pacific, ${ }^{62}$ while increases in the incidence of PPNG have also resulted in changes in treatment protocols for gonorrhoea in many developed countries including Britain, ${ }^{63}$ Australia, ${ }^{64}$ New Zealand, ${ }^{26}$ and the USA. ${ }^{65}$

\section{Defining population subgroups for targeted interventions}

(1) Behavioural surveys

Surveillance and epidemiological surveys tell us that the distribution of different STDs varies markedly between populations. HIV and the less common bacterial STDs, such as syphilis, chancroid, and in some countries gonorrhoea, tend to be markedly uneven in their distribution, with much higher prevalences in some sexually active groups than others. ${ }^{66}$ Genital chlamydia, on the other hand, tends to exhibit much less pronounced variation in prevalence rates between sexually active population groups. ${ }^{28-31}$ These observations suggest that control strategies must be different for different STDs. For viral STDs affecting a large proportion of the population and with a duration of infectiousness that cannot be significantly shortened with treatment, control efforts must be based on decreasing transmissibility through behavioural interventions, rather than through improvements in medical treatment or partner outreach. Efforts to control focal diseases like syphilis, should be targeted to specific populations. Efforts to control the more ubiquitous bacterial diseases, such as chlamydial infection, should be aimed at the much larger subpopulation at risk, adolescents and sexually active young adults.

Defining and identifying different behavioural groups is a prerequisite of a targeted approach to STD control. There is a growing body of literature on behavioural surveys and epidemiological studies with large behavioural components that have added greatly to our understanding of the transmission dynamics and current prevalence of STDs in defined populations. Much of the initial evidence on the aetiology of AIDS came from case control studies that addressed behavioural issues. ${ }^{67-69}$ More recently, large, population based surveys of sexual behaviour ${ }^{70}$ have provided data that help in the interpretation of the differential distribution of STDs in different populations. In Britain, data from the sexual attitudes and lifestyles survey have provided insight into the geographical and age group differences in STD epidemiology and have been used in the estimation of the number of HIV infected individuals in the population. ${ }^{21}$

Surveillance systems and epidemiological studies should provide data that will inform health education and identify target groups for primary prevention messages. Although population-based surveys of sexual behaviour have been undertaken, such as those in the United Kingdom ${ }^{70}$ and France, ${ }^{71}$ they are expensive, time consuming, and subject to measurement error. ${ }^{72}$ Alternative epidemiological methods, that are cheaper and less prone to measurement error, are emerging for monitoring behavioural change and identifying risky behaviours. Cowan et al have shown that antibody to herpes simplex virus type 2 may be suitable for use as an objective, serological marker of patterns of sexual behaviour in different populations. ${ }^{73}$ The unlinked anonymous HIV prevalence monitoring programme in England and Wales has also demonstrated that serological markers of HIV and hepatitis B infection can be used to monitor risk behaviour. ${ }^{56}$

\section{(2) Core groups}

One of the most important advances in our understanding of the determinants of the epidemiology of STDs was the development of the concept of the "core" group. The term "core" was originally introduced to refer to subgroups of the population that experience high rates of transmission of gonorrhoea. ${ }^{74}$ The concept of a core group comes from an analysis of the factors required to maintain the basic reproductive rate (that is, the number of secondary infections an infectious individual produces in a fully susceptible population) above one for a sexually transmitted disease. In mathematical terms the reproductive rate can be expressed as:

$$
\mathrm{R}_{0}=\beta \mathrm{cD}
$$

$R_{0} \quad$ reproductive rate

$\beta$ average probability that infection is transmitted from an infected person to a susceptible person

c average rate at which new sexual partners are acquired

D average duration of infectiousness

For most individuals in a population the rate at which new sexual partners are acquired is substantially lower than the rate at which immune responses or medical interventions eliminate or reduce the infectivity of an STD pathogen. A core group is one composed of individuals whose average rate of acquisition of new sexual partners is sufficiently high to maintain the reproductive rate above one. The critical value for $c$, above which the reproductive rate will be maintained above one, varies according to STD pathogen, owing to variations in factors such as the virulence of organisms, duration of infectiousness of patients, proportion of asymptomatic infections, and duration of acquired immunity.

Subsequent epidemiological analyses supported this theoretical concept by demonstrating the existence of small, definable, sexually active groups that maintain the endemicity of gonorrhoea through intragroup sexual contact. ${ }^{75}$ Within core groups there appear to be subsets that tend mainly to interact sexually with other members of the core (assortive mixing) and subsets that interact with individuals outside the core (disassortative mixing) spreading infection beyond the core. ${ }^{76}$ The core group concept should have a major impact on STD control programmes, ${ }^{77}$ since 
all cases in a population are either directly or indirectly caused by the core. Targeting efforts in detection and treatment towards core members should therefore be particularly effective in preventing further cases. D'Costa and colleagues calculated that repeated three week interventions among prostitutes in Nairobi would prevent two-thirds of infections and would be cost-effective. ${ }^{78}$ Over and Piot have estimated that by curing or preventing 100 cases of syphilis among a core group, approximately $1200 \mathrm{HIV}$ infections linked to those 100 episodes of syphilis could be prevented over the subsequent 10 year period. ${ }^{79}$ An epidemiological analysis by Rothenberg and Voight ${ }^{80}$ of reported outbreaks of PPNG from Europe and North America led the authors to conclude that the initiation of specific control measures should be guided by an assessment of not only the number of cases but also whether cases are members of core groups, and that control strategies should focus resources on core-group transmitters. Empirical support for these recommendations comes from Ramstedt et al in their report on the use of the serologic classification of strains to track outbreak cases in the control of a PPNG outbreak in Gothenburg. ${ }^{81}$

Core groups have been identified in several surveys: young people and poor people have been identified as key target groups in both developed and developing countries. ${ }^{82}{ }^{83}$ In the United States it has been found that coregroup members are also characterised by nonwhite ethnicity and inner city residence, ${ }^{77}$ while in developing countries, prostitutes and their male clients are the most visible members in core groups. ${ }^{78485}$ Further investigation still needs to be made into how we can identify core groups and use that information in control programmes. In particular, we need to identify markers other than repeated gonorrhoea infection that can be used to define core-group membership and focus control efforts, to identify the sexual and health behaviours that define core groups for each of the major STDs, and the determinants of those behaviours and how stable are they over time. ${ }^{77}$ The next great challenge in STD control is to determine which behaviours or patient characteristics are important in the maintenance of the hyperendemicity of STDs in particular groups. We will need to define the specific relationship between these variables, and establish how these variables are modified by demographic and sociocultural factors on the one hand, and health education and disease reduction interventions on the other. Unravelling these issues will require collaboration between clinicians, epidemiologists, and social scientists experienced in the study of behaviour.

\section{Evaluation of interventions}

Surveillance allows us to set targets and to measure our performance towards those targets. The decline of gonorrhoea and syphilis incidence in the developed world demonstrate that control programmes that reduce the dura- tion of infectivity, such as early diagnosis and treatment and partner notification, reduce the spread of these diseases. ${ }^{83}$ In England, the target set for reducing the incidence of gonorrhoea by $1995^{86}$ was achieved by $1993 .{ }^{87}$ The results of the Mwanza study provide the first real evidence at the population level that enhanced control of STDs can reduce the incidence of HIV..$^{43}$ Other notable examples of successful interventions documented through the results of epidemiological studies or through changes in surveillance data include the randomised placebo-controlled study of the use of zidovudine for the prevention of HIV transmission from mother to infant ${ }^{88}$ and the Thai government's HIV-control programme based on condom use. ${ }^{44}$ These successes should not lead to a sense of complacency. Evidence for the need for further investment in STD control is to be found in the data in developed countries on the incidence of viral STDs, and the continuing, and growing, epidemic of STDs, including HIV and bacterial STDs, in many developing countries. ${ }^{6}$

Successful interventions should be documented so that they might stimulate the implementation of similar interventions elsewhere. Often, however, the documentation of a fall in incidence following the introduction of new control measures has less desirable consequences. Falls in reported cases of syphilis and gonorrhoea after the post war peak in the 1940 s led to a reduction of resources allocated to STD control in the United States, ${ }^{47}$ Canada $^{89}$ and Britain, ${ }^{90}$ shortly before the rise in STD incidence in the 1960s. More recently, Stall has described the response to the falling incidence of STDs and falling indices of behavioural risk among gay men in the mid1980 s, by those responsible for funding AIDS prevention efforts, as the "tendency to declare victory in the fight against AIDS and then to leave the field", with "disastrous" consequences for gay male communities. ${ }^{3}$ Certainly, the reversal of the downward trend in gonorrhoea and other STDs among homosexual males at the end of the $1980 \mathrm{~s}^{649192}$ provided important evidence of the need to sustain preventive efforts within gay male communities. These observations epitomise the way that over the last 100 years political interest in STDs has waxed and waned as rates rose and fell. They also demonstrate that surveillance must continue in the face of falling incidence, to provide an early warning of the re-emergence of disease or unsafe behaviour, so that control measures can be renewed or strengthened. The process of setting and reviewing targets for disease control can be helpful in this context. As disease incidence falls, so targets can be revised, maintaining the momentum of control programmes; as incidences fall to very low levels targets may be set for the elimination of a disease, such as the WHO target for the elimination of congenital syphilis by the year $2000 .{ }^{93}$ High quality surveillance data are essential for the setting of targets, if they are to be both challenging and achievable, and for monitoring progress towards those targets. 
Surveillance data can challenge as well as support assumptions about the effectiveness of control and prevention measures. HIV testing and counselling has become an accepted part of HIV prevention in many countries, based, in part, on the premise that the knowledge that an individual has HIV infection will influence subsequent sexual behaviour. There is recent evidence, however, from the unlinked anonymous survey of HIV seroprevalence among GUM clinic attenders in England and Wales that substantial numbers of HIV infected homo/bisexual men attending GUM clinics continue to practise unsafe sex despite being aware of their anti-HIV status. ${ }^{94}$ Surveillance results such as these provide an audit of control programmes. In this case they suggest a failure to deliver health education messages, or a lack of effectiveness of those messages, both for those at highest risk for acquiring HIV and for those who have been diagnosed as being HIV infected.

The importance of evaluation of behavioural intervention was recently highlighted by Oakley et al..$^{95}$ In their review of behavioural interventions for HIV/AIDS, the authors stress that evaluations of interventions must be based on sound methodologies, identifying the following four core criteria for such studies: employing control groups, providing pre- and post-intervention data, and reporting all targeted outcomes. In their review, Oakley et al. found that of 68 separate reports of outcome evaluations located, only 18 were judged to be methodologically adequate. In another review of sexual health interventions for young people, only two of the sound evaluations recorded interventions which were effective in showing an impact on young peoples sexual behaviour. ${ }^{96}$ The authors conclude that a randomised controlled trial should be undertaken, using the best evidence available, of a sexual health intervention for young people with 5-10 years of follow-up.

\section{Stimulus to further research}

Routine surveillance systems will not usually provide data that explain the cause of detected changes (although they might provide some clues), but should act as the catalyst for further research, be it epidemiological, clinical or behavioural. There are numerous examples of how surveillance of STDs has prompted further investigation of the cause of changes or differences in disease frequency or distribution. These range from the investigation of the cause of high levels of venereal diseases among British troops in the nineteenth century to research into the reasons for global variations in the epidemiology of HIV infection. Priority areas for future research that will facilitate the interpretation of data from surveillance systems and epidemiological studies include: further analysis of the relationship between core and non-core groups within the population and how that relationship affects the epidemiology of STDs in the population as a whole; the role of STDs in the progression of HIV disease and the impact of HIV infection on other STDs; and the effect of STD control programmes on HIV transmission.

\section{The future}

Surveillance systems in most countries have inevitably been shaped by the infrastructure of clinical services for STDs in those countries. In many developing countries the infrastructure of clinical services is fragile and sometimes poorly developed. The development of suitable infrastructures for surveillance in these countries is a priority for the control of STDs, particularly now that it has been shown that treatment programmes for STDs, informed by data on local aetiology and antibiotic resistance, can have a significant effect on HIV transmission. ${ }^{43}$ This will require political commitment and resources, but the potential benefits are considerable, and needs to be done quickly as demographic shifts towards greater numbers of young adults within the population, and population shifts from rural to urban areas in many of these countries increase the potential scale of the problem. ${ }^{97}$

During the era when antibiotic-sensitive, and frequently symptomatic, bacterial infections dominated the epidemiology of STDs, data from specialist clinical services for STD patients provided information that was sufficient for the planning of control and prevention programmes and for the evaluation of their effectiveness. New surveillance systems are now required to provide data on patients that are not seen in these specialist centres: more complete data are needed on patients attending private physicians, better data are needed on children and adolescents, and data are needed on cases from non-core groups, particularly asymptomatic cases, that are seen in mainstream health services other than GUM or STD clinics.

Over the last 20 years viral agents have emerged as the major cause of STD in developed countries, and with this change in the aetiological mix of STD cases the focus of prevention and control of STDs has shifted from treatment and partner notification towards health education. Now that programmes need to be directed more towards the control and prevention viral infections and asymptomatic chlamydia infections, particularly in developed countries, surveillance systems will need to adapt if they are to continue to provide data that can be used to determine the need for public health action and to assess the effectiveness of programmes. Surveillance and epidemiological studies must now be developed such that they not only tell us that the incidence of STDs is changing, but why it is changing, and not only who to target with interventions, but what those interventions should be. We also need to continue to develop new ways of presenting surveillance data to inform policy makers and clinical and public health practitioners. The importance of surveillance and epidemiology in the control of STDs is set to increase in the face of the changing pattern STD aetiology. The challenge to clinicians and epidemiologists is to 
work together in developing systems that will inform new approaches to control and prevention.

I thank Dr Angus Nicoll and Dr Ruth Leyton for their helpful comments on an earlier draft of this paper.

1 Prevention of Acquired Immune Deficiency Syndrome (AIDS): Report of Inter-Agency Recommendations. MMWR 1983;32:101-3

2 Hunt AJ, Davies PM, Weatherburn P, Coxon APM, McMannus TJ. Changes in sexual behaviour in a large cohort of homosexual men in England and Wales, 1988-9. BMF 1991;302:505-6.

3 Stall R. How to lose the fight against AIDS among gay men. Declare victory and leave the field. $B M \mathcal{F} 1994$ : 309:685-6.

4 Catchpole MA. Sexually transmitted diseases in England and Wales: 1981-1990. Communicable Disease Repor 1992;2:R1-7.

5 Division of STD/HIV Prevention. Sexually transmitted disease surveillance, 1994. U.S. Department of Health and Human Services, Public Health Service. Atlanta: Centers for Disease Control and Prevention, October 1995.

6 Global Programme on AIDS. An overview of selected curable sexually transmitted diseases. Geneva: WHO August 1995.

7 Last JM. ed. A Dictionary of Epidemiology. 2nd ed. New York: Oxford University Press, 1988.

8 Day S, Ward $\mathrm{H}$, Harris JRW. Prostitute women and public health. $B M 7$ 1988;297:1585.

9 Marx R, Aral SO, Rolfs RT, Sterk CE, Kahn JG. Crack, sex, and STD. Sex Transm Dis 1991;18:92-101.

10 Cowan FM. Mindel A. Sexually transmitted diseases in children: adolescents. Genitourin Med 1993;69:141-7.

11 Division of STD/HIV Prevention. Sexually transmitted disease surveillance, 1993. U.S. Department of Health and Human Services, Public Health Service. Atlanta: Centers for Disease Control and Prevention, December 1994

12 Laga $M$. Epidemiology and control of sexually transmitted diseases in developing countries. Sex Transm Dis 1994; 21:(Supp1 2) S45-50.

13 The World Bank. World Development Report 1993: Investing in health. New York: Oxford University Press 1993.

14 Hall LA. "The Cinderella of Medicine": sexually-transmitted diseases in Britain in the nineteenth and twentieth centuries. Genitourin Med 1993;69:314-9.

15 Wyke TJ. Hospital facilities for, and diagnosis and treatment of, venereal disease in England, 1800-1870. $\mathrm{Br} f$ Venereal Dis 1973;49:78-85.

16 Fessler A. Venereal disease and prostitution in the reports of the poor law commissioners, 1834-1850. Brf Venereal Dis 1951;27:154-57.

17 MacDougall $\mathrm{H}$. Sexually transmitted diseases in Canada, 1800-1992. Genitourin Med 1994;70:56-63.

18 Weindling P. Sexually transmitted diseases between imperial and Nazi Germany. Genitourin Med 1994;70:284-9.

19 WHO Expert Committee on Venereal Diseases and Treponematoses. WHO Technical Report Series, No. 736. Geneva, WHO 1986

20 Global Programme on AIDS, World Health Organisation. Unlinked anonymous screening for the public health surveillance of HIV infections. Proposed international guidelines. lance of HIV infections.

21 Report of Working Group (Chairman Professor N.E. Day). The incidence and prevalence of AIDS and prevalence of other severe HIV disease in England and Wales for 1995-1999: projections using data to the end of 1994 . Communicable Disease Report 1996;6:R1-24.

22 Mardh P-A. Notes on currently used public health measures for sexually transmitted diseases. Sex Transm Dis 1994;21:(Suppl 2) S90-92.

23 Greco D, Giuliani M, Suligoi B, Panetta M, Gianetti A. Sexually transmitted diseases in Italy: clinical returns versus statutory notifications. Genitourin Med 1990;66: 383-6.

24 Hart G, Adler MW, Stapinski A, Mroczkowski TF, Wiesner PJ. Evaluation of sexually transmitted diseases control programs in industrialized countries. In: Holmes KK, Mardh P-A, Sparling PF, Weisner PJ eds, Sexually Transmitted Diseases, 2nd ed. New York, McGraw-Hill, 1990:1031-40.

25 Adler MW, Belsey EM, Rogers JS. Sexually transmitted diseases in a defined population of women. BMF 1981; 283:29-32.

26 Lyttle PH. Surveillance report: disease trends at New Zealand sexually transmitted disease clinics 1977-1993. Genitourin Med 1994;70:329-35.

27 Suligoi B, Giuliani M, Binkin N, and STD Surveillance Working Group. The national STD surveillance system in Italy: results of the first year of activity. Int $\mathcal{F} S T D$ AIDS 1994;5;93-100.

28 Duthie SJ, Hobson D, Tait IA, Pratt BC, Lowe N, Sequeira PJL, Hargreaves C. Morbidity after termination of pregnancy in first trimester. Genitourin Med 1987;63: $182-7$.

29 Blackwell AL, Thomas PD, Wareham K, Emery SJ. Health gains from screening for infection of the lower genital tract in women attending for termination of pregnancy. Lancet 1993;342:206-10.

30 Fish ANJ, Fairweather DVI, Oriel JD, Ridgway GI Chlamydia trachomatis infection in a gynaecology clinic population. identification of high-risk groups and the value of contact tracing. Eur $\mathcal{F}$ Obstet Gynecol Reprod Biol
1989;31:67-74

31 Dryden MS, Wilkinson M, Redman M, Millar MR Detection of Chlamydia trachomatis in general practice urine samples. Br $\mathcal{F}$ Gen Practic 1994;44:114-17.

32 Stergachis A, Scholes D, Heidrich FE, Sherer DM, Holmes $\mathrm{KK}$, Stamm WE. Selective screening for Chlamydia trachomatis infection in a primary care population of women. Am F Epidemiol. 1993;138:143-53.

33 Humphreys JT, Henneberry JF, Rickard RS, Beebe JL. Cost-benefit analysis of selective screening criteria of Chlamydia trachomatis infection in women attending Colorado Family Planning Clinics. Sex Transm Dis 1992; 19:47-53.

34 Masse R, Laperriere H, Rousseau H, Lefebvre J, Remis RS. Chlamydia trachomatis cervical infection: prevalence and determinants among women presenting for routine gynaecologic examination. Can Med Assoc $\mathcal{f}$ 1991;145: 953-61.

35 Ramstedt K, Forssman L, Giesecke J, Granath F. Risk factors for Chlamydia trachomatis infection in 6810 young women attending family planning clinics. Int $\mathcal{f} S T D$ AIDS 1992;3:117-2

36 Thewessen EAPM, van der Meijden WI, Doppenberg HJAT, Mulder PGH, Wagenvoort JHT, Stolz E, et al. Screening for cervical trachomatis infections in two Dutch populations. Genitourin Med 1990;66:361-6.

37 Herrman BF, Johansson AB, Mardh P-A. A retrospective study of efforts to diagnose infections by Chlamydia trachomatis in a Swedish county. Sex Transm Dis 1991;18: 233-7.

38 Lossick J, Delisle S, Fine D, Mosure D, Lee V, Smith C. Regional program for widespread screening for Chlamydia trachomatis in family planning clinics. In: Bowie WR, Caldwell HD, Jones RP, et al. eds, Chlamydial infections: Proceedings of the Seventh Chlamydial infections: Proceedings of the Seventh International Symposium on Human Chlamydial Infections.

39 Osoba AO. Sexually transmitted diseases in tropical Africa. A review of the present situation. Br $\mathcal{f}$ Venereal Dis 1981;57:89-94

40 Piot $P$, Islam MQ. Sexually transmitted diseases in the 1990 s. Global epidemiology and challenges for control. Sex Transm Dis 1994;21:(Suppl 2) S7-13.

41 Lyons $M$. Sexually transmitted diseases in the history of Uganda. Genitourin Med 1994;70:138-45.

42 Bamber SD, Hewison KJ, Underwood PJ. A history of sexually transmitted diseases in Thailand: policy and politics. Genitourin Med 1993;69:148-57.

43 Grosskurth H, Mosha F, Todd J, et al. Impact of improved treatment of sexually transmitted diseases on HIV infection in rural Tanzania: randomised controlled trial. Lancet 1995;346:530-6.

44 Hanenberg RS, Rojanapithayakorn W, Kunasol P, Sokal DC. Impact of Thailand's HIV-control programme as indicated by the decline of sexually transmitted diseases. Lancet 1994;344:243-5.

45 Meheus A, Piot P. Provision of services for sexually transmitted diseases in developing countries. In: Oriel JD, Harris JRW eds, Recent Advances in Sexually Transmitted Diseases No. 3. Edinburgh: Churchill Livingstone, 1986: 261-70.

46 Creighton C. A History of Epidemics in Britain, vol 1. London: Frank Cass \& Co, 1965:417.

47 Oriel JD. The Scars of Venus: a History of Venereology. London: Springer-Verlag, 1994:191-211.

48 Quinn TC, Mann JM, Curran JW, Piot P. AIDS in Africa: an epidemiologic paradigm. Science 1986;955-63.

49 Clottey C, Dallabetta G. Sexually transmitted diseases and human immunodeficiency virus. Epidemiologic synergy? Infect Dis Clin North Am 1993;7:753-70.

50 Wasserheit JN. Epidemiological synergy. Interrelationships between Human Immunodeficiency Virus infection and other sexually transmitted diseases. Sex Transm Dis 1992; 19:61-77.

51 Merson MH. Slowing the spread of HIV: agenda for the 1990s. Science 1993;220:1266-8.

52 World Health Organisation. Consensus statement from the consultation on global strategies for the coordination of AIDS and STD control programmes. Geneva, World Health Organisation, 1990; WHO/INF/90.2.

53 Wawer MJ, Gray RH, Quinn TC, Sewankambo NK, Wabire-Mangen F, Serwadda D, et al. Design and feasibility of population-based mass STD treatment, rural Rakai district, Uganda. In: Proceedings of the Eleventh Meeting of the International Society for STD Research; 1995 Aug 27-30; New Orleans.

54 Moses S, Manji F, Bradley JE, Nagelkerke NJD, Malisa MA, Plummer FA. Impact of user fees on attendance at a referral centre for sexually transmitted diseases in Kenya. Lancet 1992;340:463-6.

55 Groseclose SL, Erickson B, Quinn TC, Glasser D, Campbell CH, Hook III EW. Characterisation of patients accepting and refusing routine, voluntary HIV antibody testing in public sexually transmitted disease clinics. Sex Transm Dis 1994;21:31-35.

56 Report from the Unlinked Anonymous HIV Surveys Steering Group. Unlinked Anonymous HIV prevalence monitoring programme in England and Wales. London: Department

57 Harms G, Matull R, Randrianasolo D, Andriamiadana J, Rasamindrakotroka A, Kirsch T, et al. Pattern of sexually transmitted diseases in Malagasy population. Sex Transm Dis 1994;21:315-20.

58 Hayes R, Mosha F, Nicoll A, Grosskurth H, Newell J, 
Todd J, et al. A community trial of the impact of improved sexually transmitted disease treatment on the HIV epidemic in rural Tanzania: Design, AIDS 1995;9:919-926.

59 Bogaerts J, Vandepitte J, van Dyck E, Vanhoof R, Dekegel $M$, Pio $P$. In vitro antimicrobial sensitivity of Neisseria gonorrhoeae from Rwanda. Genitourin Med 1986;62: 217-20.

60 Laga M, Plummer FA, Piot P, Datta P, Namaara W, Ndinya-Achola JO, et al. Prophylaxis of gonococcal and chlamydial ophthalmia neonatorum. $N$ Engl $f \mathrm{Med}$ 1988;318:653-7.

61 Van Dyck E, Rosseau R, Duhamel M, Behets F, Laga M, Nzila $M$, et al. Antimicrobial susceptibility of Neisseria gonorrhoea in Zaire: high level plasmid-mediated tetracycline resistance in Central Africa. Genitourin Med cline resistance

62 World Health Organisation. STD treatment strategies. WHO Consultation on development of sexually transmitted diseases treatment strategies. Geneva, World Health Organisation 1989; WHO/VDT/89.447.

63 Jephcott AE. The work of the Gonococcus Reference Unit. PHLS Microbiology Digest 1992;9:155-59.

64 The Australian Gonococcal Surveillance Programme. The incidence of gonorrhoea and the antibiotic sensitivity of gonococci in Australia, 1981-91. Genitourin Med 1993; 69:364-9.

65 Antibiotic-resistant strains of Neisseria gonorrhoeae. Policy guidelines for detection, management, and control. guidelines for detection, managem

66 Toomey KE, Moran JS, Raffertey MP, Beckett GA. Epidemiological considerations of sexually transmitted diseases in underserved populations. Infect Dis Clin North Am 1993;7:739-52.

67 CDC. Pneumocystis carinii pneumonia among persons with hemophilia A. MMWR 1982;31:365-7.

68 Vieira J, Frank E, Spira TJ, Landesman SH. Acquired immune deficiency in Haitians: opportunistic infections in previously healthy Haitian immigrants. $N$ Engl $f$ Med 1983;308:125-9.

69 CDC. A cluster of Kaposi's sarcoma and Pneumocystis carinii pneumonia among homosexual male residents of cos Angeles and Orange Counties, California. MMWR Los Angeles and

70 Johnson AM, Wadsworth J, Wellings K, Field J, Bradshaw S. Sexual Attitudes and Lifestyles. Oxford: Blackwell Scientific Publications, 1994

71 Analyse des Comportements Sexuels en France investigators. AIDS and sexual behaviour in France. Nature 1992, 360:407-9.

72 Lee RM, Renzetti CM. The problems of researching sensitive topics. American Behavioural Scientist 1990;3:510-28.

73 Cowan FM, Johnson AM, Ashley R, Corey L, Mindel A. Antibody to herpes simplex virus type 2 as serological marker of sexual lifestyle in populations. BMF 1994; marker of

74 Yorke JA, Hethcote HW, Nold A. Dynamics and control of transmission of gonorrhoea. Sex Transm Dis 1978;5: $51-6$

75 Rothenberg RB. The geography of gonorrhoea: empirical demonstration of core group transmission. Am $\mathcal{F}$ Epidemiol 1983;117:688-94.

76 Rothenberg RB, Potterat JJ. Temporal and social aspects of gonorrhoea transmission: the force of infectivity. Sex Transm Dis 1988;15:88-92.

77 Brunham RC. The concept of core and its relevance to the epidemiology and control of sexually transmitted dis- eases. Sex Transm Dis 1991;18:67-8.

78 D'Costa LJ, Plummer FA, Bowmer I, Fransen L, Piot P, Ronald AR, Nsanze H. Prostitutes are a major reservoir of sexually transmitted diseases in Nairobi, Kenya. Sex Transm Dis 1985;12:64-7.

79 Over $M$, Piot $P$. HIV infection and sexually transmitted diseases. In: Jamison DT, Mosley WH, Measham AR, Bobadilla JL, eds. Disease Control Priorities in Developing Countries. New York: Oxford University Press, 1993 455-527.

80 Rothenberg R, Voigt R. Epidemiologic aspects of control of penicillinase- producing Neisseria gonorrhoeae. Sex Transm Dis. 1988;15:211-16.

81 Ramstedt KM, Hallhagen GJ, Bygdeman SM, Lincoln KA Kallings I, Gillenius C, Sandstrom EG. Serologic classification and contact-tracing in the control of microepidemics of $\beta$-Lactamase-producing Neisseria gonorrhoeae. Sex mics of $\beta$-Lactamase-producing
Transm Dis 1985;112:209-14.

82 Aral SO, Holmes KK. Epidemiology of sexual behaviour and sexually transmitted diseases. In: Holmes $\mathrm{KK}$ Mardh P-A, Sparling PF, Weisner PJ eds, Sexually Transmitted Diseases, 2nd ed. New York, McGraw-Hill, 1990:19-36

83 Kohl PK. Epidemiology of sexually transmitted diseases. Sex Transm Dis 1994;21:(Suppl 2) S81-83.

84 Plorde DS. Sexually transmitted diseases in Ethiopia: social factors contributing to their spread and implications for developing countries. Br ₹ Venereal Dis 1981;57:357-62.

85 Meheus A, De Clercq A, Prat R. Prevalence of gonorrhoea in a Central African town. Br f Venereal Dis 1974;50: in a 2 .

86 The Health of the Nation: $A$ Consultative Document for Health in England. Cm 1523. London: HMSO, 1991.

87 New cases seen at NHS genito-urinary medicine clinics in England: 1993 annual figures. London, Department of Health, SD2B, 1994.

88 Zidovudine for the prevention of HIV transmission from mother to infant. MMWR 1994;43:285-7.

89 Peart AFW. The venereal disease problem in Canada. Can $\mathcal{F}$ Publ Health 1952;44:160-6.

90 King A. "These dying diseases" venereology in decline? Lancet 1958;i:651-7.

91 Handsfield HH, Schwebke J. Trends in sexually transmitted disease in King County, Washington, 1980-90. Sex Transm Dis 1990;17:221-5.

92 Evans BG, Catchpole MA, Heptonstall J, Mortimer JY McGarrigle CA, Nicoll AG, et al. Sexually transmitted diseases and HIV-1 infection among homosexual men in England and Wales. BMF 1993;306:426-8.

93 World Health Organisation. Targets for Health for All: targets in support of the European regional strategy for health for all. Copenhagen: WHO Regional Office for Europe, 1985.

94 Catchpole MA, Mercey DE, Nicoll A, Rogers PA, Simms I, Newham J, et al on behalf of the Collaborative Group. Continuing sexually transmitted disease transmission among HIV 1 infected attenders at genitourinary medicine clinics in England and Wales. $B M \mathcal{F} 1996 ; 312$ : cine clinic

95 Oakley A, Fullerton D, Holland J. Behavioural interventions for HIV/AIDS prevention. AIDS 1995;9:479-86.

96 Oakley A, Fullerton D, Holland J, Arnold S, FranceDawson M, Kelley P, McGrellis S. Sexual health education interventions for young people: a methodological review. BMF 1995;310:158-62.

97 Brown ST, Zacarias FRK, Aral SO. STD control in less developed countries: the time is now. Int $\mathcal{f}$ Epidemio 1985;14:505-9. 